mutations accumulating in field isolates of H5N1 could "get us to be a little more attentive to revving up the capability of expanding the doses of vaccine we have".

But others say that such mutants are unlikely to be spotted in time. Moreover, they say, governments are unlikely to take the political or economic risks of plunging ahead with a vaccine on the basis of a putative pandemic threat. "Nobody is going to ramp up production of a pre-pandemic vaccine based on these two experimental viruses," says Webby. “That's 100\% sure." Ab Osterhaus, a co-author on Fouchier's paper also at Erasmus, agrees that industry will wait on the actual pandemic strain for any major roll-out, but says that screening for mutations could detect variants that could be used to make new seed strains, which might help with the initial response.

Daniel Perez, a virologist at the University of Maryland in College Park, has argued that the lab strains themselves could be added to the current panel of prepandemic vaccine strains. But the existing pre-pandemic vaccines are probably just as good. For vaccine purposes, what counts most is the overall antigenic properties of the virus's two surface proteins, haemagglutinin (HA) and neuraminidase (NA).

"The antigenicity of the virus depends less on any mutations than on where the HA and NA come from," says Ilaria Capua, an avian-flu researcher at the Veterinary Public Health Institute in Legnaro, Italy. Seed strains representing the major variants of circulating HA and NA are regularly revised for use in pre-pandemic vaccines.

In any case, vaccine makers seem unlikely to take substantial pre-emptive action, regardless of any ominous changes in wild H5N1. Bram Palache, the global government affairs director for vaccines at Abbott Biologicals in Weesp, the Netherlands, says that industry will not switch its limited plant capacity from making the seasonal flu vaccines to making a pandemic vaccine until a human pandemic has actually emerged and government orders are in hand. And once a pandemic is under way, neither industry nor governments will be content to use existing pre-pandemic vaccines - they will insist on one matched to the pandemic strain itself, says Palache.

Given the current technology and infrastructure, developing and manufacturing such a vaccine will take many months. Now that the mutant-flu studies have suggested that an $\mathrm{H} 5 \mathrm{~N} 1$ pandemic is a real possibility, health authorities should focus on shortening that timescale, says Farrar. He urges much greater investment in better and faster vaccine technologies, including universal flu vaccines - because H5N1 is far from the only possible pandemic strain. - SEE EDITORIAL P.131

\title{
Japan finds a key to unlock philanthropy
}

\section{Latest Kavli centre beats legal hurdle to using endowments.}

\section{BY DAVID CYRANOSKI}

$\int \mathrm{a}$ apan's universities and research institutes have long had to make do with few philanthropic donations. Strict laws governing university finances, and the lack of a philanthropic tradition, have discouraged the gifts that serve Western institutions so well.

But change is coming. This week, the University of Tokyo unveils the country's first institute named after a foreign donor: the Kavli Institute for the Physics and Mathematics of the Universe.

The announcement adds Norwegian philanthropist Fred Kavli's name, along with a US\$7.5-million endowment, to one of Japan's most successful institutes. Launched at the university in 2007 as one of the country's five World Premier International Research Centers (WPIs) (see Nature 447, 362-363; 2007), the Institute for the Physics and Mathematics of the Universe (IPMU) has become an international force in black-hole and dark-matter research. Run by Hitoshi Murayama of the University of California, Berkeley, the IPMU has an international mix that is uncharacteristic in Japan, something that helped it to

\section{"Japan's system is catching up with the West."} gain the only 'S' (superior) grade among the WPIs from Japan's increasingly strict science funders in last year's interim evaluations. Last year, the university created the Todai Institutes for Advanced Study — which gives the IPMU a permanent organizational home. But converting the IPMU into a Kavli institute was a more arduous feat.

"It actually caused stirs and ruffled some feathers," says Murayama. Some argued that the endowment was insufficient to merit naming rights, and accused the researchers of "selling our souls for money", he says.

But the government has pushed Japan's cash-starved universities to seek external funds, and the IPMU, despite gaining a place in the University of Tokyo's organizational unit, did not have secure funding. So when the Kavli Foundation in Oxnard, California, approached Murayama to offer its support, he jumped at the chance.

Japan's university law, however, does not allow public universities to put money into high-yield but risky investment schemes. That makes it nearly impossible for institutions to use the returns on an endowment to continuously support themselves, as the other 15 Kavli institutes do. "You're better off just spending the endowment," says Murayama.

To get around this, instead of handing the endowment over to the IPMU, the Kavli Foundation will continue to manage the sum, giving the institute the return on the funds. "It has told us that if the system in Japan ever changes, the money is ours," says Murayama.

Murayama says that the money will allow the IPMU to continue wooing foreign researchers by, for example, finding jobs for spouses and helping to place researchers' children in international schools. The ministry considers such expenditures to be "personal matters" and not reimbursable with public funds.

Having found a way to solve the philanthropy problem, the university is keen to try it again. "I hope to build on this momentum and redouble our efforts to pursue reform" of the systems for managing donated funds, says university president Junichi Hamada.

Hiroshi Komiyama, chairman of the Mitsubishi Research Institute in Tokyo, and past-president of the University of Tokyo, hopes that the Kavli deal "will be a great trigger for other universities" to get more external funding through endowments.

That will require a much broader change, however. In 2007, charitable donations in Japan amounted to only $0.11 \%$ of the country's gross domestic product, compared with $2.2 \%$ in the United States and $0.80 \%$ in the United Kingdom, which Komiyama blames on the relatively even distribution of wealth in Japan. Tough rules on the creation of non-profit organizations that aim to organize charitable giving have also held back giving (see Nature 450, 24-25; 2007).

A law enacted last year - and another that will come into effect in April - should ease the rules on setting up non-profit organizations. The laws also increase the tax exemptions for individuals donating to non-profit organizations or private universities. These will not bring direct benefit to public universities, but they could open the way for new non-profit organizations that could collect $\rightarrow$ NATURE.COM For our recent series on philanthropy, see: go.nature.com/26hnhi and manage funds for the universities. "Japan's system is catching up with the West," says Komiyama. - 